\title{
OPTIMIZATION OF WOOD FLOUR ACETYLATION BY FACTORIAL DESIGN AND PARTIAL LEAST SQUARES REGRESSION
}

Lisandra M. K. Nadal, Daniele C. Cararo e Luís A. Pinheiro*

Departamento de Engenharia de Materiais, Universidade Estadual de Ponta Grossa, Av. Gal. Carlos Cavalcanti, 4748, 84030-900

Ponta Grossa - PR, Brasil

Rosilene A. Prestes

Coordenação de Alimentos, Universidade Tecnológica Federal do Paraná, Campus de Ponta Grossa, Av. Monteiro Lobato, km 4, 84016-210 Ponta Grossa - PR, Brasil

Recebido em 5/1/12; aceito em 17/5/12; publicado na web em 24/8/12

\begin{abstract}
Acetylation was performed to reduce the polarity of wood and increase its compatibility with polymer matrices for the production of composites. These reactions were performed first as a function of acetic acid and anhydride concentration in a mixture catalyzed by sulfuric acid. A concentration of 50\%/50\% (v/v) of acetic acid and anhydride was found to produced the highest conversion rate between the functional groups. After these reactions, the kinetics were investigated by varying times and temperatures using a $3^{2}$ factorial design, and showed time was the most relevant parameter in determining the conversion of hydroxyl into carbonyl groups.
\end{abstract}

Keywords: acetylation; factorial design; partial least square regression.

\section{INTRODUCTION}

Advances achieved by researchers and growing concerns over viable reuse of waste have resulted in establishing polymer matrix composites (PMCs) reinforced with wood flour as a technology employed worldwide. ${ }^{1}$ The use of wood fibers or wood flour as fillers in thermoplastics has been known since the 1970s in the automotive industry, which uses polypropylene/wood flour composites called Woodstock $^{\circledR}{ }^{2,3}$ Today, research in this field has become increasingly important in helping manufacturers to tailor competitive wood products for a wider range of applications. ${ }^{4-16}$

Two aspects must be considered: composite processing, since factors such as degradation and residence time are important parameters that influence properties, ${ }^{17-21}$ and compatibility between the materials' phases. ${ }^{7}$ Wood plastic composites (WPC) have limited applications due to the intrinsic properties of wood, such as its hydrophilicity and the relatively low dimensional stability of lignocellulosic components. Water absorption by wood affects its interfacial quality and compromises its mechanical properties. To attenuate this problem, several approaches have been tested to enhance the compatibility between wood particles and polyolefin matrices by modifying the interfacial interactions in these composites. ${ }^{1,22}$

Cellulose is a polysaccharide whose structure is compounded by the constant repetition of the glucose molecule. ${ }^{23}$ This molecule has high polarity due to the three hydroxyl groups in its constitution, providing strong intermolecular bonding. This is the reason why pure cellulose does not exhibit thermoplastic behavior, i. e., undergoes melt transition like synthetic polymers. Many reagents have been tested to modify the cell-wall components and improve adhesion, with varying degrees of success, including acid chloride, isocyanates, aldehydes, alkyl halides, anhydrides, lactones, nitriles, etc. Among these reagents, the chemical modification of lignocellulose using acetic anhydride is perhaps the simplest, safest and cheapest method for improving the strength, dimensional stability and rot resistance of wood flour.

Hydroxyl groups are the most abundant and reactive sites for polymers in the cell wall of lignocellulosic materials. ${ }^{11,23}$ The reaction

*e-mail: lapinheiro@uepg.br of these hydroxyl groups with acetic anhydride forms ester bonds in cell walls of the wood and in intercellular regions, creating stable acetate groups (Equation 1) that reduce the hydrophilicity of cell-wall components, decrease the wood's polarity and improve interfacial adhesion with the polymer, increasing the resistance to degradation and durability of WPC..$^{14,24}$

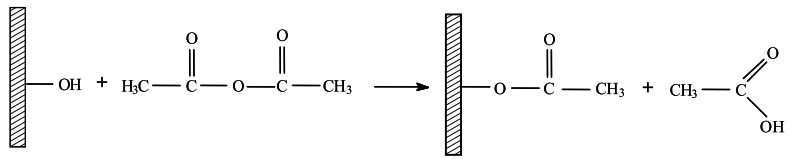

In this reaction, the hydrogen atom that belongs to cellulose hydroxyl is replaced by an acetic group from acetic anhydride, yielding a carboxylic acid and an ester group in the wood, which is less polar to strong hydroxyl. This strategy renders wood more compatible with apolar polymers such as polyolefins.

Hence, the objectives of this study were to verify the effects of the proportion of acetic acid/anhydride on the acetylation of wood flour at varying times and temperatures and to examine hydroxyl and carbonyl groups by FTIR. The influence of these parameters was verified by experiments with a factorial design and partial least squares regression, both useful techniques for obtaining information concerning the effect of parameters in a given process. ${ }^{25-28}$

\section{EXPERIMENTAL}

\section{Materials}

Wood flour (100 mesh) from Pinus sp. trees, with a density of 0.25 $\mathrm{g} / \mathrm{cm}^{3}$, was supplied by Pinhopó Ltda. Acetic acid and acetic anhydride (both from Biotec) were used in different ratios in the acetylation treatments, and the reaction was catalyzed by sulfuric acid (Biotec).

\section{Methods}

Wood flour acetylation

Acetylation was performed according to the method described by Lisperguer et al.. ${ }^{11}$ The wood flour was oven-dried at $105^{\circ} \mathrm{C}$ for 6 
$\mathrm{h}$ prior to preparing the samples. The resultant flour was then treated by mixing $5 \mathrm{~g}$ of flour in $100 \mathrm{~mL}$ of a mixture of reagents and $2 \mathrm{~mL}$ of sulfuric acid. The experiments were performed in two steps. First, the acetylation time and temperature were kept constant at $60^{\circ} \mathrm{C}$ for $2 \mathrm{~h}$, using varying ratios of 100:0, 75:25, 50:50, 25:75, and 0:100 of acetic acid and anhydride. After identifying the best reagent ratio, the acetylation kinetics were studied at varying times and temperatures. The chemical treatment was applied at 60,70 , and $80{ }^{\circ} \mathrm{C}$ for 1,2 , and $4 \mathrm{~h}$. In both treatments, after the acetylation step, the wood flour was washed in ethanol to remove excess chemicals, filtered and oven-dried at $105^{\circ} \mathrm{C}$ for $2 \mathrm{~h}$.

\section{Fourier transform infrared spectroscopy (FTIR)}

Samples were analyzed by Fourier transform infrared spectroscopy (Nicolet 4700 spectrometer) to determine the concentrations of carbonyl $(\mathrm{C}=\mathrm{O})$ and hydroxyl $(\mathrm{OH})$ groups. Treated wood flour was mixed with potassium bromide at $1 \%(\mathrm{w} / \mathrm{w})$. The mixture was pressed into a sample holder and examined spectroscopically. Spectra were recorded for $40 \mathrm{scans}$ at 4000 to $400 \mathrm{~cm}^{-1}$, with a resolution of $2 \mathrm{~cm}^{-1}$.

\section{Multivariate analysis}

To determine the effect of acetic anhydride and acid concentrations on the wood's chemical modification, FTIR spectra were subjected to multivariate calibration by partial least squares (PLS) regression using Infometrix Pirouette 4.1 software. The data were mean-centered and the regression was cross-validated.

\section{Factorial design}

The effect of varying the acetylation parameters was evaluated from empirical models based on the factorial design method, using the aforementioned concentration ratios of carbonyl and hydroxyl groups. These values were matricized and the data fitted empirically to an equation using suitable software. For all the tested models, the significance of their coefficients and the regression equation were determined statistically by $t$ and $F$ tests, respectively. This evaluation involved testing two parameters, namely, temperature $(\mathrm{T})$ and time $(\mathrm{t})$.

\section{RESULTS AND DISCUSSION}

\section{Influence of chemical concentrations on acetylation kinetics}

Wood cellulose consists of units that have three hydroxyl groups, producing a strong band in FTIR spectra at $3500 \mathrm{~cm}^{-1}$, as indicated in Figure 1. Considering that acetylation treatment causes hydroxyl



Figure 1. Comparative spectra of wood flour before (a) and after (b) acetylation reaction with acetic acid and anhydride 50/50 (v/v) groups to convert into carbonyl groups, their FTIR absorption spectra are expected to show differences. As the figure indicates, the hydroxyl peak of treated wood decreased, while the carbonyl peak at $1750 \mathrm{~cm}^{-1}$ increased. This peak was attributed to ester produced during the acetylation reaction.

The spectral data of all the treated samples were used in a partial least squares regression (PLS) to identify the influence of chemical concentration on their spectra. PLS is a mathematical tool that enables the construction of a polynomial (Equation 2) which correlates, specifically in this case, FTIR spectra with the changes in functional groups as a function of acetic acid/anhydride ratio.

$\hat{y}=b_{1} \cdot x_{1}+b_{2} \cdot x_{2}+b_{3} \cdot x_{3}+\cdots+b_{i} \cdot x_{i}$

where $\hat{y}$ is the concentration of acetic acid or anhydride, $x_{i}$ is the absorbance value for the $i$-th infrared wavenumber and $b_{i}$ its respective coefficient. Absorbance values were used as independent variables and the concentrations of acetic acid and anhydride as dependent variables. In this analysis it was decided to perform the regression for the acetic acid concentration; however, since the sum of the chemicals must be $100 \%$, the same results would probably have been found for acetic anhydride. With regard to cross-validation during PLS regression, Figure 2 shows good correlation between measured and predicted values of acid concentration for a linear regression, since the calibration $\left(\mathrm{r}_{\text {cal }}\right)$ and validation $\left(\mathrm{r}_{\mathrm{val}}\right.$ ) coefficients were 0.9998 and 0.992 , respectively.

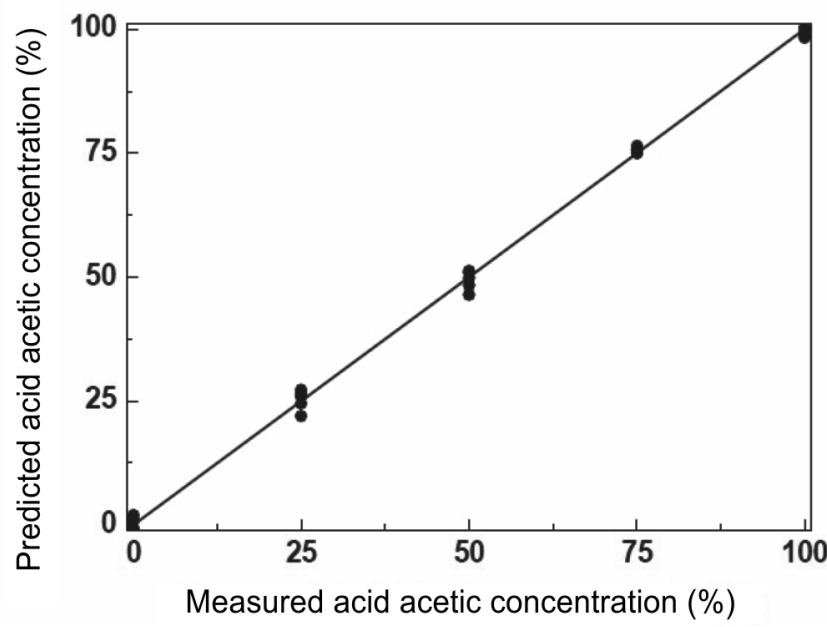

Figure 2. Regression plot of measured vs. predicted acid concentrations

Figure 3 shows the regression vector, which corroborates the results given in Figure 1, i.e., hydroxyl and carbonyl bands are the most affected and the hydroxyl concentration decreases with acid concentrations, while carbonyl concentration increases. Since the absorbance peak is directly related to group concentration, according to the Lambert-Beer law, this indicates that the hydroxyl groups were converted into carbonyl groups.

Figure 4 illustrates the absorbance ratio of carbonyl and hydroxyl as a function of chemical concentrations. The results shown represent an average of 5 measurements and the standard deviation bars confirm the accuracy of the measurements. Results showed that this conversion was more pronounced at the concentration of 50/50 (v/v); therefore, this composition was employed to reduce the polarity of the wood flour for use in the polymer composites.

\section{Influence of time and temperature on acetylation kinetics}

The above-described measurements indicated that the optimal 


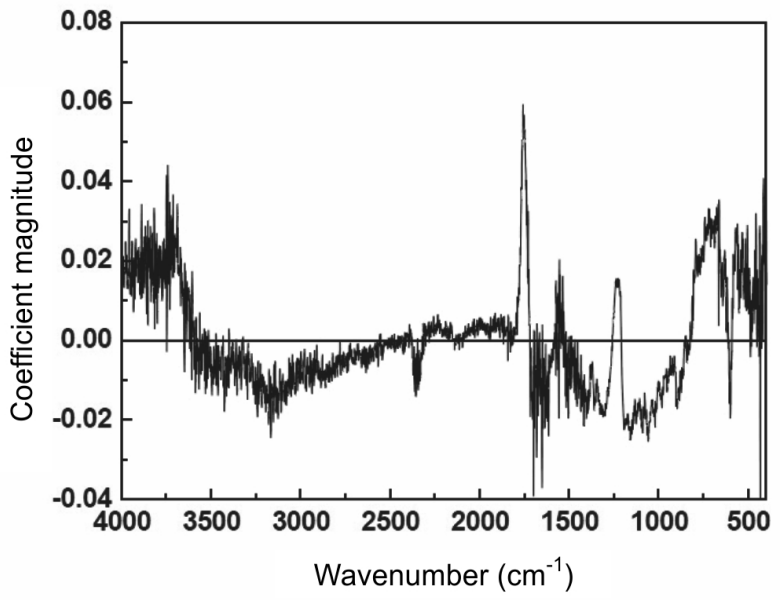

Figure 3. Regression vector for the correlation between wood spectra and chemicals concentration

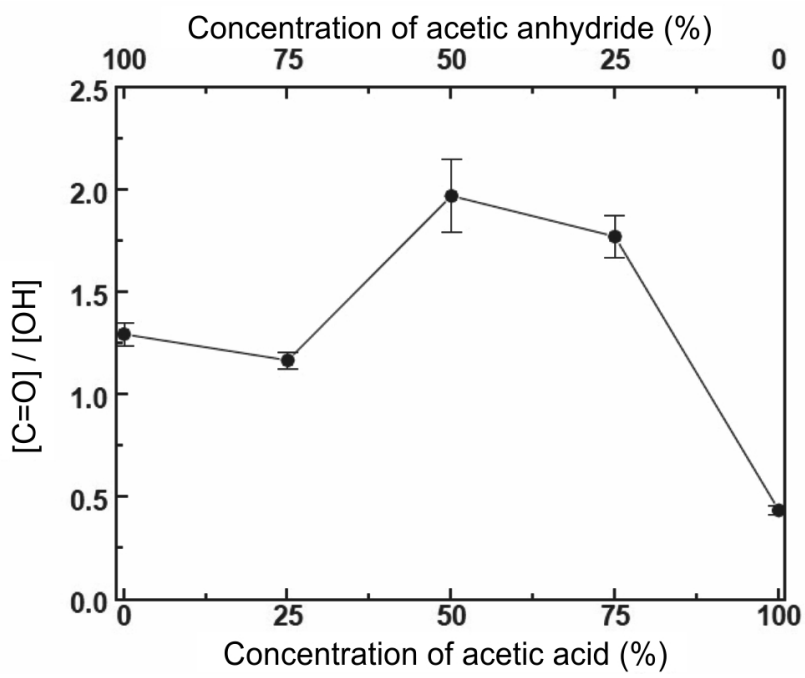

Figure 4. Absorbance ratio of carbonyl and hydroxyl groups as a function of acetic acid and anhydride concentration

composition to convert hydroxyl groups into carbonyl groups was $50 / 50(\mathrm{v} / \mathrm{v})$. The next step was to determine the influence of time and temperature on the acetylation kinetics, while keeping this composition constant. Akin to all chemical reactions, acetylation is affected by these parameters. However, the purpose of these experiments was to determine and quantify this influence. Table 1 shows the variation in the absorbance ratio of carbonyl and hydroxyl as a function of acetylation time and temperature.

The maximum error calculated for the replications performed for each condition was $7.2 \%$. The $[\mathrm{C}=\mathrm{O}] /[\mathrm{OH}]$ ratio increased in response to increasing time and temperature, despite the decrease for $2 \mathrm{~h}$ at 80 ${ }^{\circ} \mathrm{C}$. To determine the magnitude of influence of acetylation time and temperature, a linear multiple regression was performed, using a $3^{2}$ factorial design. Thus, the magnitude of time and temperature, as well as their interactions, were calculated and plotted, as illustrated in Figure 5.

The statistical significance of the parameters and regression were verified by $t$ and $F$ tests, respectively, assuming a $95 \%$ level of confidence. The regression coefficient $\left(r^{2}\right)$ was 0.90 . The results indicated that time was the most influential parameter, since the value of its coefficient was 40-fold higher than that of temperature. Therefore, the conversion of hydroxyl into carbonyl groups is more strongly affected by time. The values of these coefficients were used to build a response surface, illustrated in Figure 6, which shows a quadratic
Table 1. Absorbance ratio of carbonyl and hydroxyl groups as a function of acetylation time and temperature of a 50/50 (v/v) mixture of acetic acid and anhydride

\begin{tabular}{ccc}
\hline Temperature $\left({ }^{\circ} \mathrm{C}\right)$ & Time $(\mathrm{h})$ & {$[\mathrm{C}=\mathrm{O}] /[\mathrm{OH}]$ ratio } \\
\hline 60 & 1 & $1.848 \pm 0.0355$ \\
& 2 & $1.686 \pm 0.0534$ \\
& 4 & $5.129 \pm 0.1041$ \\
\hline 70 & 1 & $3.014 \pm 0.0659$ \\
& 2 & $3.657 \pm 0.0619$ \\
& 4 & $4.237 \pm 0.0493$ \\
\hline 80 & 1 & $6.797 \pm 0.4896$ \\
& 2 & $2.314 \pm 0.0368$ \\
& 4 & $6.113 \pm 0.2525$ \\
\hline
\end{tabular}

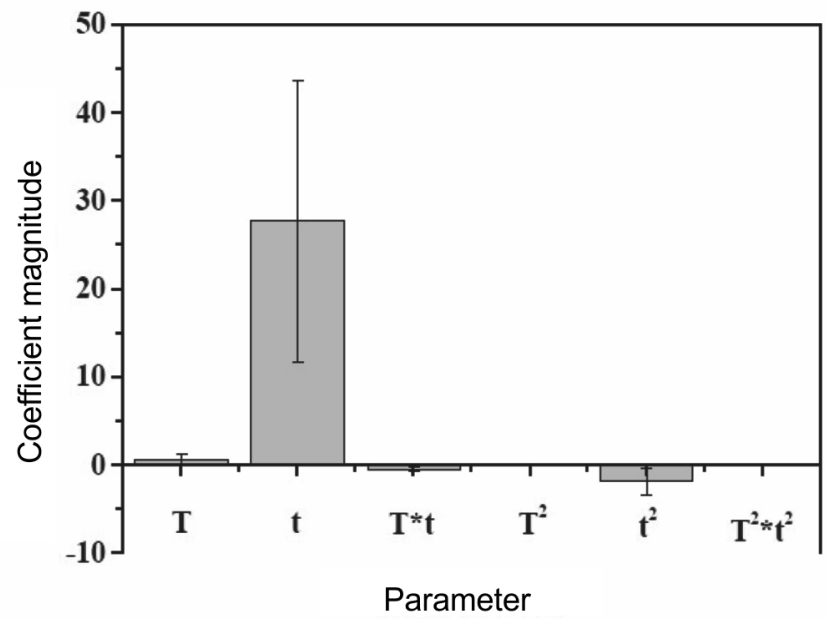

Figure 5. Coefficient magnitude of time and temperature parameters

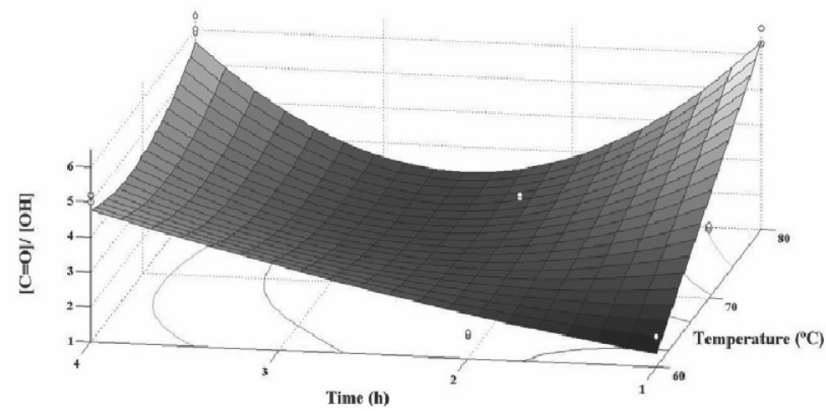

Figure 6. Surface response of carbonyl and hydroxyl absorbance ratio as function of time and temperature

relationship between the parameters and the $[\mathrm{C}=\mathrm{O}] /[\mathrm{OH}]$ ratio.

The spectra in Figure 7, which compares the regions at 3500 and $1750 \mathrm{~cm}^{-1}$ of untreated wood and wood acetylated at $60{ }^{\circ} \mathrm{C}$, were plotted to corroborate these results. With increasing treatment time, the band at $3500 \mathrm{~cm}^{-1}$ showed a pronounced decrease, while the band at $1750 \mathrm{~cm}^{-1}$ increased. Since these spectra were recorded from samples containing the same concentration, the spectra did not have to be normalized and the changes in absorbance can be observed directly.

\section{CONCLUSIONS}

To reduce the polarity of wood flour and increase its compatibility with polymer matrices for the production of composites, acetylation 


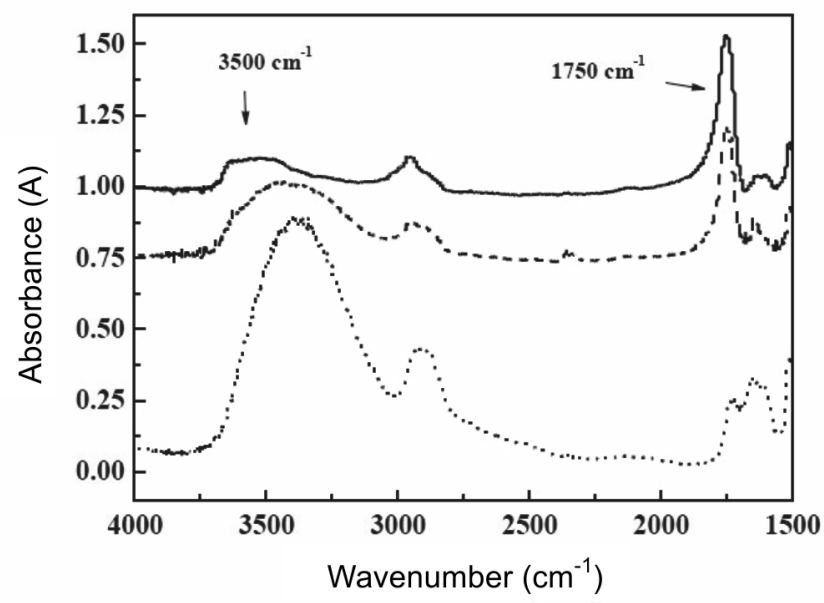

Figure 7. Spectra of: (...) untreated wood; (---) treated at $60{ }^{\circ} \mathrm{C}$ for $1 \mathrm{~h}$; (-) treated at $60^{\circ} \mathrm{C}$ for $4 \mathrm{~h}$

reactions were performed with varying concentrations of acetic acid and anhydride. The FTIR spectra indicated that the acetylation reactions caused the hydroxyl groups to convert into carbonyl groups, signifying a reduction in polarity. PLS regression revealed that the most affected bands were 3500 and $1750 \mathrm{~cm}^{-1}$, corresponding to hydroxyl and ester carbonyl groups, respectively. The accuracy of this regression was confirmed by the values of $\mathrm{r}^{2}{ }_{\text {val }}$ and $\mathrm{r}^{2}$ cal obtained. A mixture of $50 \% / 50 \%(\mathrm{v} / \mathrm{v})$ acetic acid and anhydride was found to yield the highest ratio of carbonyl to hydroxyl groups. This mixture was used to determine the influence of time and temperature on the acetylation kinetics. These two parameters increased the carbonyl-to-hydroxyl ratio, but multiple linear regression using a $3^{2}$ factorial design indicated that time was the more influential parameter. This regression and the parameters calculated from it proved to be statistically significant on $t$ and $F$ tests.

\section{ACKNOWLEDGEMENTS}

The authors thank Pinhopó Ltda. for donating the wood flour used in this study and Fundação Araucária and CNPq (Brazil) for their financial support.

\section{REFERENCES}

1. Dányádi, L.; Móczó, J.; Pukánszky, B.; Compos. A 2010, 41, 199.

2. Zhang, Y.; Toghiani, H.; Zhang, J.; Xue, Y.; Pittman, C. U.; J. Mater. Sci. 2009, 44, 2143.
3. Correa, C. A.; Fonseca, C. N. P.; Neves, S.; Polímeros: Ciência e Tecnologia 2003, 13, 154.

4. Ali, K. M.; Khan, M. A.; Balo, S. K.; Ahmad, M. U.; J. Appl. Polym. Sci. 1998, 67, 79.

5. Ashori, A.; Nourbakhsh, A.; Bioresour. Technol. 2010, 101, 2515.

6. Borysiak, S.; Polym. Bull. 2010, 64, 275.

7. Dányádi, L.; Janecska, T.; Szabó, Z.; Nagy, G.; Móczó, J.; Pukánsky, B.; J. Compos. Sci. Technol. 2007, 67, 2838.

8. Hansmann, C.; Weichslberger, G.; Gindl, W.; Wood Sci. Technol. 2005, $39,502$.

9. Inari, G. N.; Petrissans, M.; Gerardin, P.; Wood Sci. Technol. 2007, 41, 157.

10. Kaboorani, A.; J. Compos. Mat. 2009, 43, 2599.

11. Lisperguer, J.; Droguett, C.; Ruf, B.; Nuñez, M.; J. Chil. Chem. Soc. 2007, 52, 1073

12. Matsunaga, M.; Kataoka, Y.; Matsunaga, H.; Matsui, H.; J. Wood Sci. 2010, 56, 293.

13. Papadopoulos, A. N.; Pougioula, G.; Bioresour. Technol. 2010, 101, 6147.

14. Ramsden, M. J.; Blake, F. S. R.; Wood Sci. Technol. 1997, 31, 45.

15. Ramsden, M. J.; Blake, F. S. R.; Fey, N. J.; Wood Sci. Technol. 1997, 31, 97.

16. Zhang, Y.; Xue, Y.; Toghiani, H.; Zhang, J.; Pittman. C. U.; Compos. Interfaces 2009, 16, 671.

17. Pinheiro, L. A.; Chinelatto, M. A.; Canevarolo, S. V.; Polym. Degrad. Stab. 2004, 86, 445.

18. Pinheiro, L. A.; Chinelatto, M. A.; Canevarolo, S. V.; Polym. Degrad. Stab. 2006, 91, 2324

19. Pinheiro, L. A.; Hu, G.-H.; Pessan, L. A.; Canevarolo, S. V.; Polym. Eng. Sci. 2008, 48, 806 .

20. Pinheiro, L. A.; Bitencourt, C. S.; Canevarolo, S. V.; Polym. Eng. Sci. 2010, 50, 826.

21. Melo, T. J. A.; Pinheiro, L. A.; Canevarolo, S. V.; Polímeros: Ciência e Tecnologia 2010, 20, 322.

22. Nourbakhsh, A.; Karegarfard, A.; Ashori, A.; Nourbakhsh, A.; J. Thermoplastic Compos. Mat. 2010, 23, 169.

23. Taiz, L.; Zeiger, E.; Fisiologia Vegetal, $3^{\mathrm{a}}$ ed., Artmed: São Paulo, 2004.

24. Obataya, E.; Minato, K.; Wood Sci. Technol. 2008, 42, 567.

25. Freitas, L.; Santos, J. C.; Barcza, M. V.; de Castro, H. F.; Quim. Nova 2009, 32, 2277.

26. Skeika, T.; Pessoa, C.; Fujiwara, S. T.; Nagata, N.; Quim. Nova 2010, $33,629$.

27. Vicentini, F. C.; Figueiredo, L. C. S.; Janegitz, B. C.; Santiago, A.; Pereira, E. R.; Fatibello-Filho, O.; Quim. Nova 2011, 34, 825.

28. da Cunha, A. P.; da Cunha, V. D. P.; Silveira, L.; Martin, A. A.; Quim. Nova 2003, 26, 850 . 